\title{
Presynaptic HCN channels constrain GABAergic synaptic transmission in pyramidal cells of the medial prefrontal cortex
}

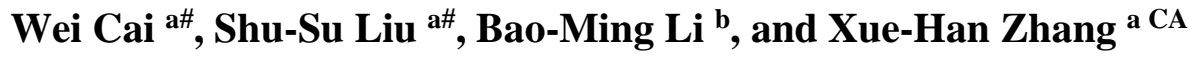 \\ ${ }^{a}$ Institute of Neurobiology and State Key Laboratory of Medical Neurobiology, Institutes of Brain \\ Science, Fudan University, Shanghai 200032, China \\ ${ }^{b}$ Center for Neuropsychiatric Diseases, Institute of Life Science, Nanchang University, Nanchang \\ 330031, China \\ \#, The two authors contribute equally
}

Address correspondence to: Xue-Han Zhang, Ph.D.

Institute of Neurobiology, Institutes of Brain Sciences, and

Fudan University,

Shanghai 200032,

China

Email: $\quad$ xuehanzhang@fudan.edu.cn 


\begin{abstract}
Hyperpolarization-activated cyclic nucleotide-gated $(\mathrm{HCN})$ channels are widely expressed in neurons in the central nervous system. It has been documented that HCN channels regulate the intrinsic excitability of pyramidal cells in the medial prefrontal cortex (mPFC) of rats. Here, we report that $\mathrm{HCN}$ channels limited GABAergic transmission onto pyramidal cells in the mPFC. Pharmacological block of HCN channels resulted in a significant increase in the frequency of both spontaneous and miniature inhibitory postsynaptic currents (IPSCs) in mPFC pyramidal cells. Such facilitation effect on mIPSCs required presynaptic $\mathrm{Ca}^{2+}$ influx and reversed by high-dose cAMP. Such facilitation did not exist in the presence of the T-type $\mathrm{Ca}^{2+}$ channel selective blockers. Immunofluorescence staining revealed that HCN channels expressed in presynaptic GABAergic terminals, as well as in both soma and neurite of parvalbumin-expressing (PV-expressing) basket cells in the mPFC. The present results indicate that HCN channels in GABAergic interneurons, most likely PV-expressing basket cells, constrain inhibitory control over layer 5-6 pyramidal cells through restricting presynaptic $\mathrm{Ca}^{2+}$ entry.
\end{abstract}

Key words: GABAergic transmission; $\mathrm{HCN}$ channel; $\mathrm{mPFC}$; rats 


\section{Introduction}

Hyperpolarization activated cyclic nucleotide-gated $(\mathrm{HCN})$ channels are richly expressed in the central nervous system, which are consist of four either identical or nonidentical subunits (HCN1-4)[1], are activated with membrane hyperpolarization, and are regulated directly by cAMP [2-4]. HCN channels conduct a current called $\mathrm{I}_{\mathrm{h}}$, which contributes to resting potential and input resistance. HCN channels have a major role in controlling neuronal intrinsic excitability, dendritic integration of synaptic potentials, synaptic transmission, and rhythmic oscillatory activity in individual neurons and neuronal networks [4-9].

HCN channels are principally located in pyramidal cell dendrites, although they are found at lower densities in the soma of pyramidal neurons as well as other neuron subtypes[10]. Somato-dendritic HCN channels in pyramidal neurons modulate spike firing and synaptic potential integration by influencing the membrane resistance and resting membrane potential[10]. In addition to their dendritic localization, $\mathrm{HCN}$ channels are expressed in cortical and hippocampal axons and synaptic terminals of inhibitory and excitatory neurons [5, 9, 11-13]. Additionally, presynaptic $\mathrm{HCN}$ current, $\mathrm{I}_{\mathrm{h}}$, has been indicated to affect excitatory synaptic transmission in invertebrate neurons and vertebrate neurons where $I_{h}$ has been shown to influence excitatory transmitter release [14-17] via affecting the activities of presynaptic terminal $\mathrm{Ca}^{2+}$ channels [17]. Additionally, presynaptic $\mathrm{I}_{\mathrm{h}}$ affect inhibitory neurotransmission in the rodent globus pallidus, cerebellum and hippocampus $[12,13,18,19]$, though the mechanism by which this occur is unknown.

The prefrontal cortex (PFC) plays a critical role in cognitive functions. The PFC is composed of two major neuronal populations: glutamatergic pyramidal neurons and $\gamma$ -aminobutyric acid (GABAergic) interneurons. Although GABAergic interneurons only account for approximately $20 \%$ of the cortical neuronal population, they are critical elements of cortical circuits by providing feedforward and feedback inhibition and generating synchronous and 
rhythmic network activity [20].

Although GABAergic interneurons are a minority of the neuron population in the PFC (10\%-20\%), each interneuron could control hundreds to thousands of pyramidal cells through its profuse local axonal arborizations. Somatostatin, Calretinin, Parvalbumin (PV)-expressing basket cells comprise $\sim 50 \%$ of GABAergic neuron population in the neocortex [21]. Axons of PV-expressing basket cells preferentially target the soma and proximal dendrites of pyramidal cells, forming multiple inhibitory synapses with a high probability of GABA release [21-24]. Thus, PV-expressing basket cells exert a powerful inhibitory control over pyramidal cells and are likely to constitute the dominant inhibitory system in the PFC.

It has been reported that peri somatic inhibition ensured by basket cells also has a powerful regulatory effect on the synchronization and oscillation of pyramidal cells [22, 25]. Neuronal synchronization and oscillation are necessary for the execution of cognitive functions [26], and abnormal synchronization and oscillation in the PFC may result in cognitive deficits seen in psychiatric disorders [27]. Wang et al. reported that the $\alpha_{2 \mathrm{~A}}$ adrenoceptor-cAMP-HCN channel signaling pathway in monkey prefrontal cortical cells plays an important role in maintaining the delay-period persistent firing, as such facilitating working memory, although the cell-type localization of HCN channels remains to be identified [28].

However, little is known about the role of HCN channels in GABAergic interneurons of the cortex in GABAergic transmission. The present study attempted to examine if and how HCN channels in interneurons regulates inhibitory synaptic transmission onto layer 5-6 pyramidal cells in the medial prefrontal cortex of rats, using immunofluorescence staining and whole-cell recording approaches. 


\section{Results}

\section{HCN channels limit GABAergic transmission onto pyramidal cells}

To examine whether $\mathrm{HCN}$ channels are involved in regulating GABAergic synaptic transmission in the mPFC, we recorded action potential-dependent spontaneous IPSCs (sIPSC) in layer 5-6 pyramidal cells in the presence of $20 \mu \mathrm{M}$ DNQX and $50 \mu \mathrm{M}$ D-APV with $-70 \mathrm{mV}$ holding potential (Fig. 1A). The recorded sIPSCs could be completely blocked by the GABA receptor antagonist bicuculline $(10 \mu \mathrm{M})$ (data not shown). Under the control experimental condition, the frequency of sIPSC, especially, large sIPSCs (amplitude >20pA) was $1.95 \pm 0.37 \mathrm{~Hz}$, and it increased to $3.28 \pm 0.5 \mathrm{~Hz} 12-15$ min after bath application of $\mathrm{HCN}$ channel blocker ZD7288 (30 $\mu \mathrm{M})$ (Fig. 1C; $p<0.01$, paired $t$-test, $\mathrm{n}=6$ cells). The facilitation effect of ZD7288 was largely reversible 12-15 min after termination of ZD7288 (Fig. 1C; $2.62 \pm 0.31 \mathrm{~Hz}$ after washout). The enhancement of the frequency of large sIPSCs in pyramidal cells indicates that HCN channels limit GABAergic transmission onto pyramidal cells. 


\section{Figure 1}

A

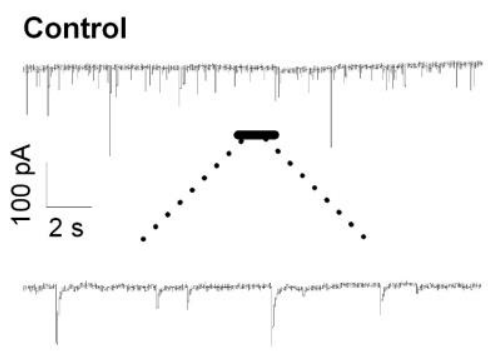

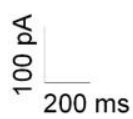

B1

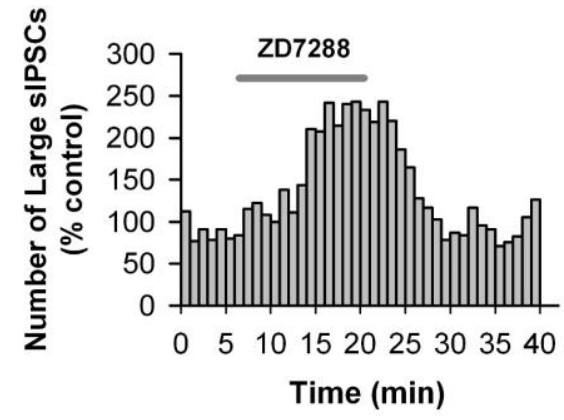

C

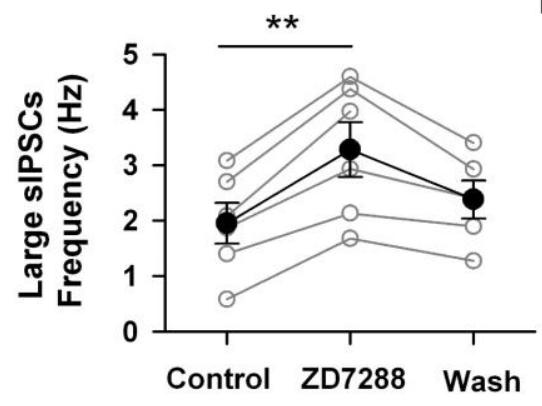

ZD7288

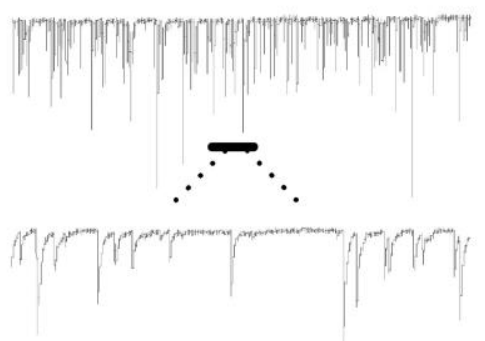

B2

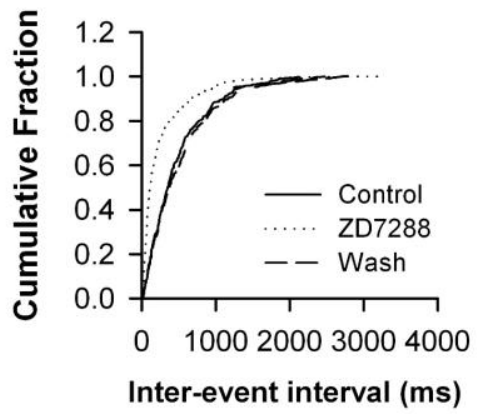

D

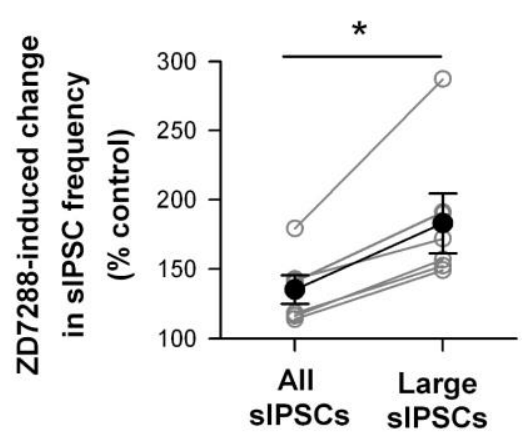

\section{Blockade of HCN channels increases the frequency of sIPSCs.}

A. An example trace of spontaneous IPSCs (sIPSCs) recorded in mPFC pyramidal cell in absence (Control) or presence of HCN channel blocker ZD7288 (30 $\mu \mathrm{M})$. Holding potential $=-70 \mathrm{mV}$.

B. ZD7288 increases the frequency of sIPSCs with large amplitude (>20 pA). The number distribution of large sIPSCs (bin=60 s; Bl), and the cumulative fraction distribution of 
inter-event intervals of sIPSCs before (Control), during (ZD7288), and after ZD7288 application (Wash; B2). Data were from the same cell in (A).

C. The summary individual (open circles) and grouped (closed circles) frequency of large sIPSCs. $\mathrm{n}=6$ cells. $* * p<0.01$

D. The sIPSC frequency changes in all detective events and large events after ZD7288 application. Open circles for the individual cell; Close circles for grouped cells. Data were from the same cell in (A). * $p<0.05$

\section{Presynaptic but not postsynaptic HCN channels are involved in limiting GABAergic transmission}

To test HCN channels affect GABAergic transmission by postsynaptic or presynaptic pathway, we test miniature IPSCs(mIPSC), which can represent responses of pyramidal cells to spontaneous release of single GABA-containing vesicles and action potential independently. Therefor mIPSCs were recorded in the presence of $1 \mu \mathrm{M}$ tetrodotoxin (TTX) that blocks action potential firing and propagation. As shown in Figure 2, the frequency of mIPSCs was $1.37 \pm 0.20$ $\mathrm{Hz}$ and the peak amplitude was $13.21 \pm 1.73$ pA under control condition. When ZD7288 $(30 \mu \mathrm{M})$ was applied, the frequency of mIPSCs increased to $2.40 \pm 0.39 \mathrm{~Hz}$ (Fig. 2D1; $p<0.01$, paired $t$-test, $\mathrm{n}=10$ cells), whereas the amplitude of mIPSCs kept unchanged (Fig. 2D2; control: 13.22 \pm 1.59 pA, ZD7288: $p>0.05$, paired $t$-test). The facilitation effect of ZD7288 on mIPSC frequency was largely recovered after termination of ZD7288 application $(2.08 \pm 0.30 \mathrm{~Hz}$ after washout; Fig. 2D1). The fast rise time of mIPSCs in the presence of ZD7288 was comparable with control (10\%-90\% rise time: $1.52 \pm 0.12 \mathrm{~ms}$ under control and $1.54 \pm 0.13 \mathrm{~ms}$ in the presence of ZD7288; $p>0.05$, paired $t$-test; Fig. 2E). Thus, ZD7288 did not change the kinetics of mIPSCs. Together, the mIPSC events regulated by ZD7288 were mainly generated in the presynaptic region of recorded pyramidal neurons [29]. These results suggested that HCN channels may limit 
presynaptic GABA release to constrain GABAergic transmission onto pyramidal cells.

To clarify whether HCN channels in postsynaptic pyramidal cells are involved in the ZD7288 facilitation effect on GABAergic transmission, we evoked postsynaptic

GABA-receptor-mediated currents by puffing GABA onto the soma of pyramidal cells, and examined the effect of ZD7288 on GABA-evoked currents. In this experiment, we only examined the effect of ZD7288 on GABA-evoked currents in the pyramidal cells with depolarizing sag to ensure the recorded pyramidal cells expressing HCN channels (Fig. 2F, left). It is well known that the depolarizing sag in response to negative current injection is a typical of response pattern in pyramidal cells expressing HCN channels in the PFC [8] and other tissues [30-32].

GABA-evoked currents recorded in the presence of TTX $(1 \mu \mathrm{M})$, DNQX $(20 \mu \mathrm{M})$ and D-APV $(50 \mu \mathrm{M})$ with $-70 \mathrm{mV}$ holding potential (Fig. 2F, middle, inset). Puff application of GABA (10 $\mu \mathrm{M})$ evoked an outward current that was completely blocked by the $\mathrm{GABA}_{\mathrm{A}}$ receptor antagonist bicuculline (10 $\mu \mathrm{M} ; \mathrm{n}=3$; data not shown). ZD7288 had no effect on the amplitude of

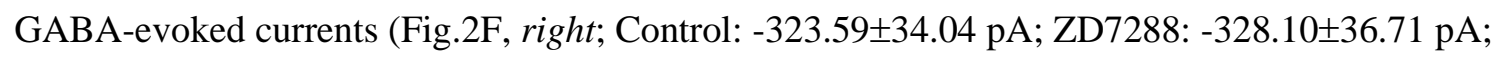
ZD7288 did not change the input resistance (Fig. 2F, middle; $108.55 \pm 3.10 \%$ of control $12-15$ min after ZD7288 application, $p>0.05$ for ZD7288 vs. control, paired $t$-test). Thus, the ZD7288-induced increase in the frequency of mIPSC was not due to the blockade of HCN channels in the pyramidal cells, but most likely resulted from the blockade of HCN channels in GABAergic terminals innervating the pyramidal cells. 


\section{Figure 2}

A

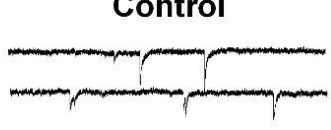

B1

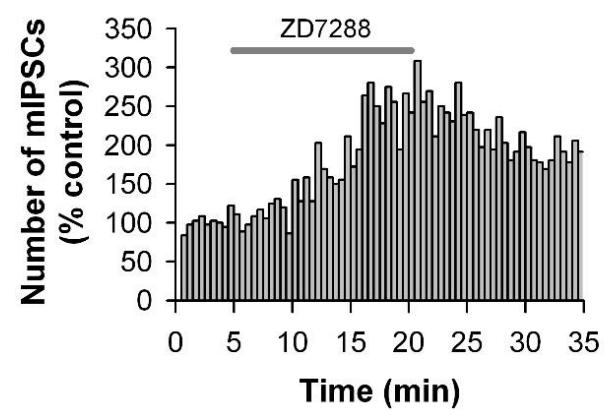

C1

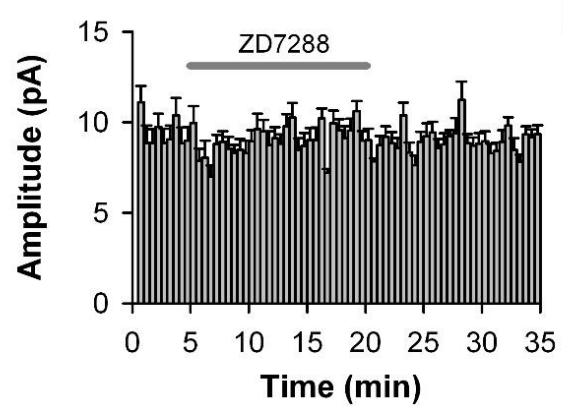

D1

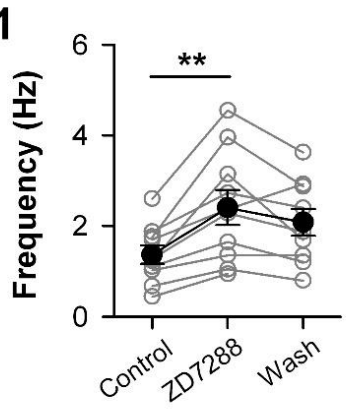

D2

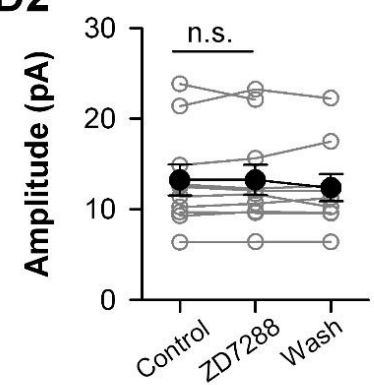

E

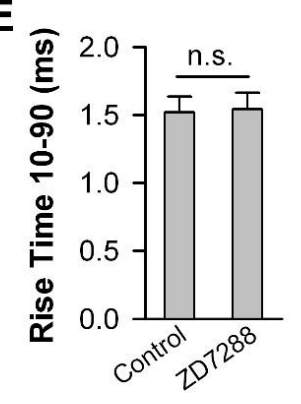

Wash

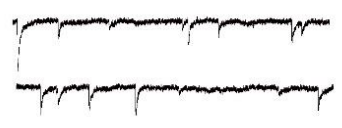

B2

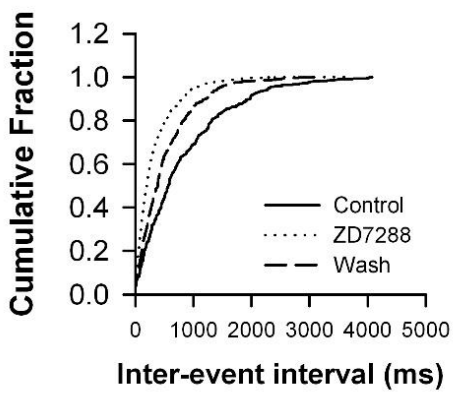

C2

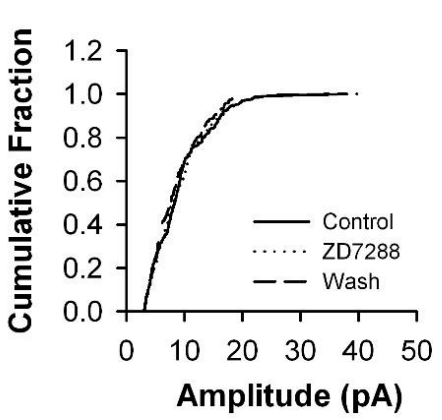

Amplitude (pA)
F

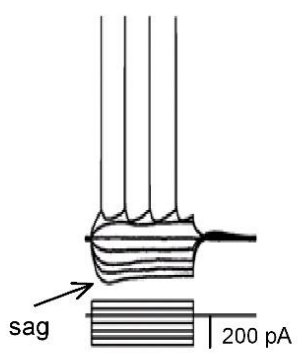




\section{Blockade of HCN channels enhances the frequency but not amplitude of mIPSCs.}

A. Representative traces of miniature IPSCs (mIPSCs) recorded in mPFC pyramidal cell before (Control), during (ZD7288), and after ZD7288 application (Wash). Holding potential: -70 mV. Calibration: 20 pA, 200 ms.

B. ZD7288 facilitates the frequency of mIPSCs. The number distribution of mIPSCs (bin=60 s, B1), and the cumulative fraction distribution of inter-event intervals of mIPSCs (B2). Data were from the same cell in A.

C. ZD7288 has no effect on the amplitude of mIPSCs. The amplitude distribution of mIPSCs (bin=60 s, C1), and the cumulative fraction distribution of mIPSC amplitude (C2). Data were from the same cell in A.

D. The mIPSC frequency (D1) and amplitude (D2) from the individual cell (open circles) and grouped cells (closed circles). $\mathrm{n}=10$ cells, ${ }^{*} p<0.01$.

E. ZD7288 has no effect on $10-90 \%$ rise time of mIPSCs. Data were from the same cells in D.

F. ZD7288 has no effect on the amplitude of IPSCs evoked by puff application of GABA (10 $\mu \mathrm{M})$ to pyramidal cells. A typical example for pyramidal cells with a sag (left). An example time course of the IPSC amplitude (black circles) and the input resistance (grey circles) obtained from the pyramidal cell. The insets show the IPSC traces in the absence (black) and presence of ZD7288 (grey), each of which is the average of seven consecutive IPSCs (middle). The summary individual (open circles) and grouped (closed circles) amplitude of IPSCs (right). $\mathrm{n}=5$ pyramidal cells. 


\section{HCN channels are present on presynaptic GABAergic terminals}

To identify that the expression of HCN channels in presynaptic GABAergic terminals, we examined the expression of $\mathrm{HCN}$ channels in GABAergic terminals using immunostaining technique. We performed immunolabeling against GAD65, the synthetic enzyme for GABA, to label GABAergic terminals[33]. We double labeled HCN1, HCN2, and HCN4 channels with GAD65. Single-plane confocal image showed that GAD immunoreactive (GAD-ir) appeared in puncta structures distributed in the neuropil, as well as around unlabeled cell bodies (Fig. 4C), which consistent with previous reports [34]. Merging single-plane images showing HCN1-ir, HCN2-ir, and HCN3-ir with showing GAD65-ir showed the puncta of GAD65-ir, surrounding the cell bodies of HCN-ir cells, partially co-located with HCN1-ir, HCN2-ir, and HCN3-ir (Fig. 4D). These data point out that HCN channels are present in the GABAergic terminals, indicating that blockade of $\mathrm{HCN}$ channels affects presynaptic GABA release. 


\section{Figure 3}
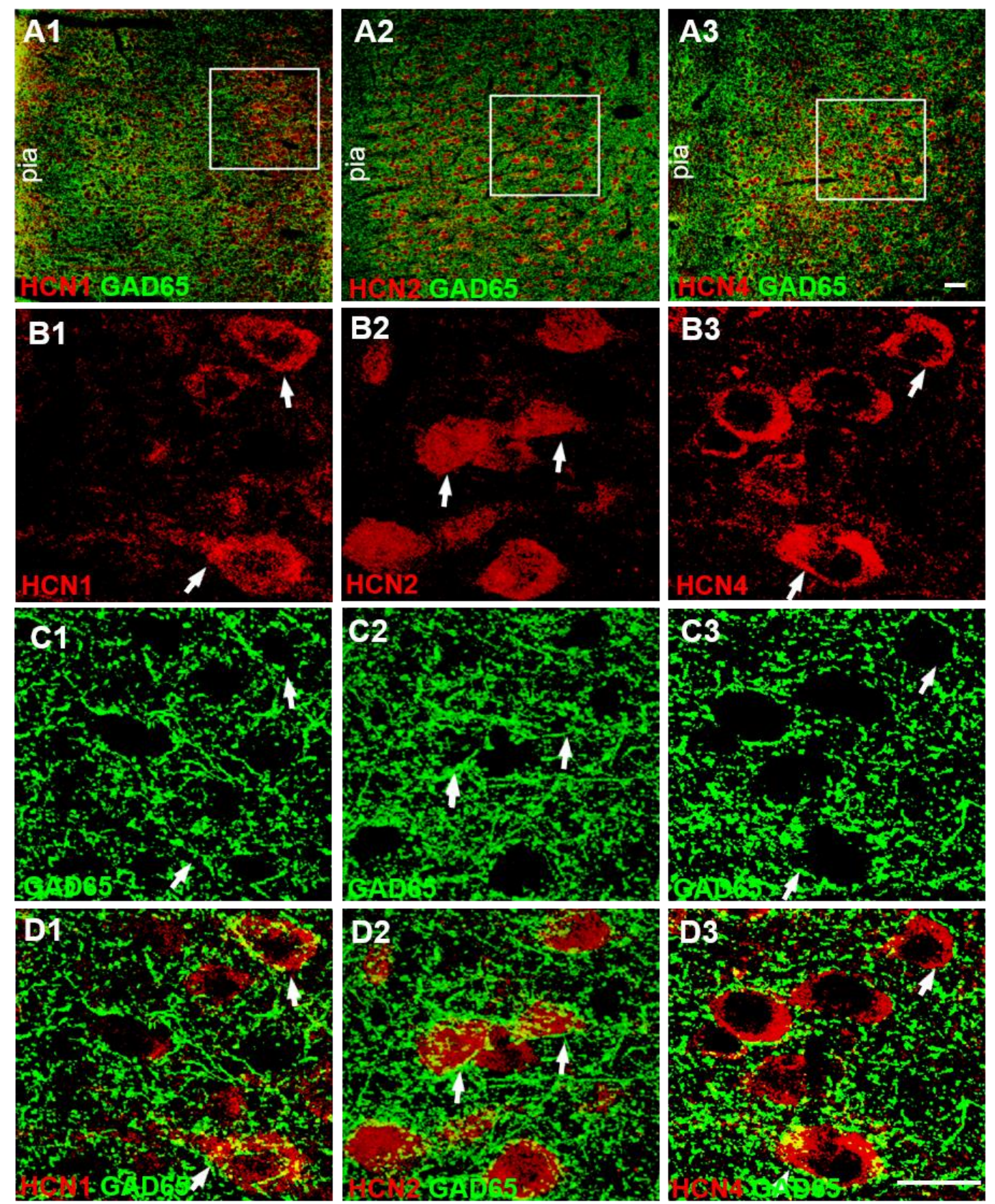


\section{HCN channels are present on GABAergic terminals in the mPFC.}

A. Low-magnification confocal images showing double stained with HCN channels (red) and GAD65 (green), a GABAergic terminal marker. The squares illustrating the cells in layer 5-6 of the mPFC. Scale bar, $40 \mu \mathrm{m}$

B and C. Single-plane confocal images showing the HCN1-ir (B1), HCN2-ir (B2), HCN4-ir (B3), and GAD65-ir (C1-C3) at high magnification. GAD65-ir appears in punctuate structures distributed in the neuropil, as well as around unlabeled pyramidal cell soma (C1-C3).

E. Merging of the paired images (B1 and C1), (B2 and C2), and (B3 and C3) shows that the puncta of GAD65-ir surround the cell bodies of HCN1-ir (B1), HCN2-ir (B2), and HCN4-ir (B3) cells. Partially overlapping areas of red (HCN) and green (GAD65) profiles showing yellow. The arrowheads indicate double-labeled cells. Scale bars represent $20 \mu \mathrm{m}$.

\section{HCN channel activation suppress GABA release}

Some researchers have pointed out that ZD7288 can activate $\mathrm{Na}^{+}$and $\mathrm{Ca}^{2+}$ channels[35, 36]. Thus, we ought to clarify this phenomenon is based on HCN channels. Activation of HCN channels is facilitated by cAMP. cAMP strongly enhances HCN channel function [37-41]. In cortex, $\mathrm{HCN}$ channels are heteromers of $\mathrm{HCN} 1$ and $\mathrm{HCN} 2$ subunits that are highly responsive to cAMP $[38,39]$. We hypothesized that up-regulation of presynaptic HCN channel function might alter GABA release onto pyramidal cells. To test this hypothesis, the frequency of mIPSC was compared after perfusion of the membrane-permeable, cAMP analog, Sp-cAMPs (200 $\mu$ M). Perfusion of Sp-cAMPs (5 min) markedly decreased the frequency of mIPSCs in pyramidal cells. Grouped data demonstrate that Sp-cAMPs (12-15 min after application) significantly decreased 
mIPSC frequency from $1.71 \pm 0.28 \mathrm{~Hz}$ to $1.26 \pm 0.24 \mathrm{~Hz}(\mathrm{p}<0.01$, paired t-test; $\mathrm{n}=5$ pyramidal cells from 2 animals; Fig. 4C). The effect of Sp-cAMPs on mIPSC frequency was largely recovered after termination of Sp-cAMPs application $(1.56 \pm 0.26 \mathrm{~Hz}$ after washout; $\mathrm{p}<0.05 \mathrm{vs}$. Sp-cAMPs treatment; paired $t$-test; Fig. 4C). This result solid our hypothesis that ZD7288 influence mIPSC through HCN channels.

\section{Figure 4}

A

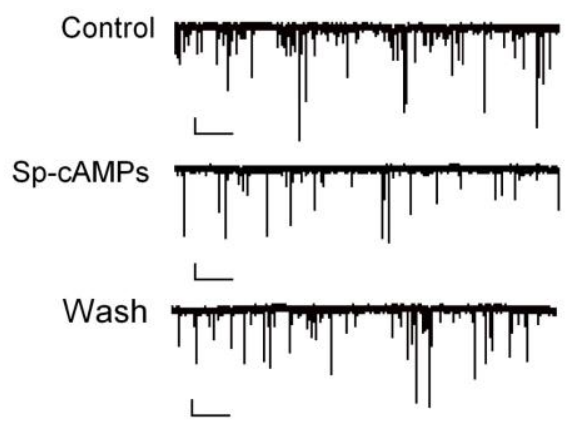

B2

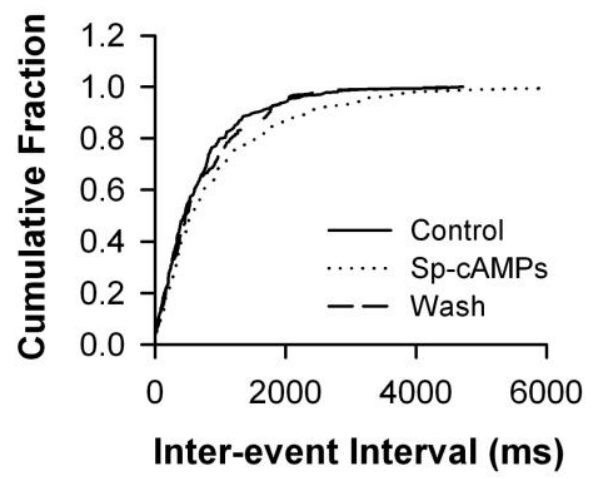

B1

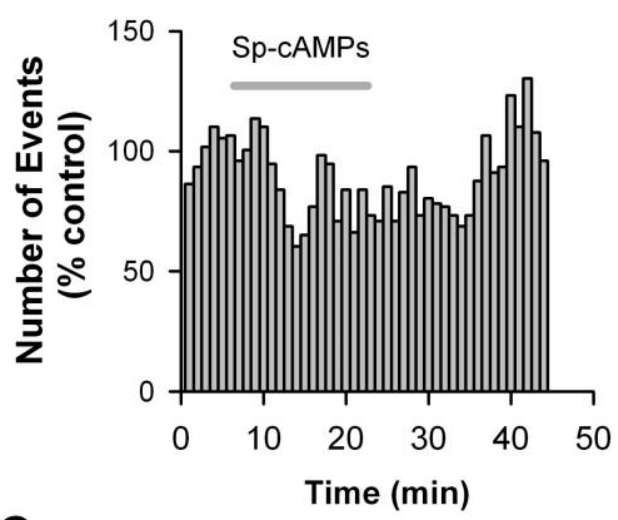

C

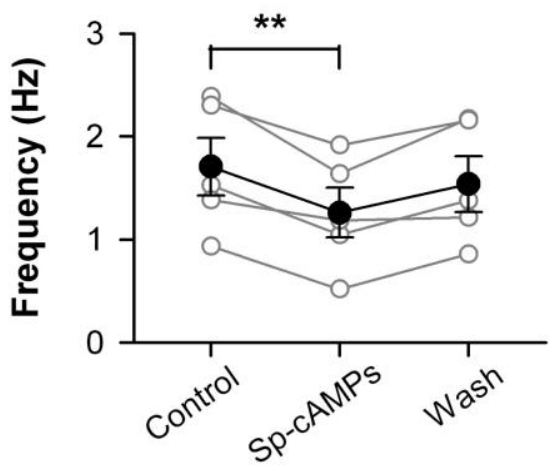




\section{Enhancing HCN channel function decreases the frequency of mIPSC.}

A. Representative traces of miniature IPSCs (mIPSCs) recorded in mPFC pyramidal cell before (Control), during (Sp-cAMPs), and after Sp-cAMPs application (Wash). Holding potential: $-70 \mathrm{mV}$. Calibration: 20 pA, $200 \mathrm{~ms}$.

B. Sp-cAMPs decreases the frequency of mIPSCs. The number distribution of mIPSCs (bin=60 $\mathrm{s} ; B 1$ ), and the cumulative fraction distribution of inter-event intervals of mIPSCs (B2). Data were from the same cell in A.

C. Summary for individual cell (open circles) and grouped cells (closed circles). $n=5$ cells, $* * p<0.01$.

\section{HCN-channel blockade facilitates GABA release via presynaptic $\mathrm{Ca}^{2+}$ influx}

It has been proved that $\mathrm{Ca}^{2+}$ influx is critical for the vesicle releasing at presynaptic membrane[42]. To examine whether $\mathrm{Ca}^{2+}$ influx is involved in the ZD7288-induced facilitation of mIPSC frequency, we first examined the effect of ZD7288 under $\mathrm{Ca}^{2+}$-free condition. As shown in Figure 3, ZD7288 failed to increase mIPSC frequency in the absence of extracellular $\mathrm{Ca}^{2+}$. The mIPSC frequency $12-15$ min after ZD7288 application was $106.4 \pm 5.27 \%$ of control $(p>0.05$, paired $t$-test, $\mathrm{n}=5$ pyramidal cells from 4 animals; Fig. $5 \mathrm{~A}$ ). We next investigated the effect of ZD7288 in the presence of $\mathrm{Cd}^{2+}(200 \mu \mathrm{M}), \mathrm{a} \mathrm{Ca}^{2+}$ channel blocker. ZD7288 significantly increased mIPSC frequency $(163.48 \pm 10.05 \%$ of control, $p<0.01$ for ZD7298 vs. control, paired t-test; Fig. 5B). Such facilitation was completely blocked when $\mathrm{Cd}^{2+}$ was added into perfusion solution $\left(108.0 \pm 5.82 \%\right.$ of control; $p<0.01$ for $\mathrm{ZD}+\mathrm{Cd}^{2+} v s . \mathrm{ZD}$ alone, paired t-test, $\mathrm{n}=6$ pyramidal cells from 3 animals). Thus, these data indicate that $\mathrm{Ca}^{2+}$ influx is required for the ZD7288-induced augmentation of mIPSC frequency. 


\section{Figure 5}

A1

B1

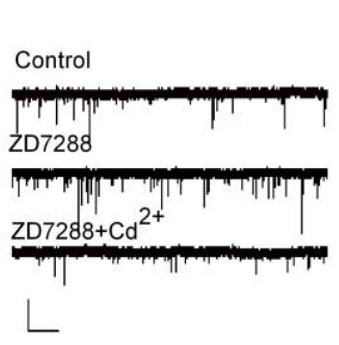

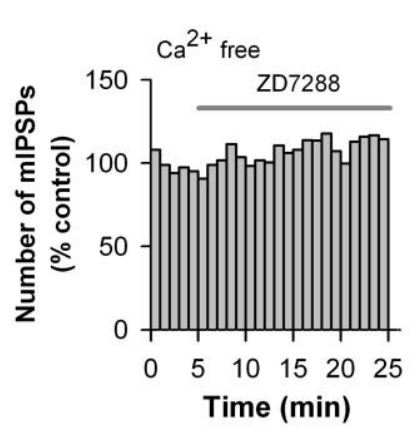
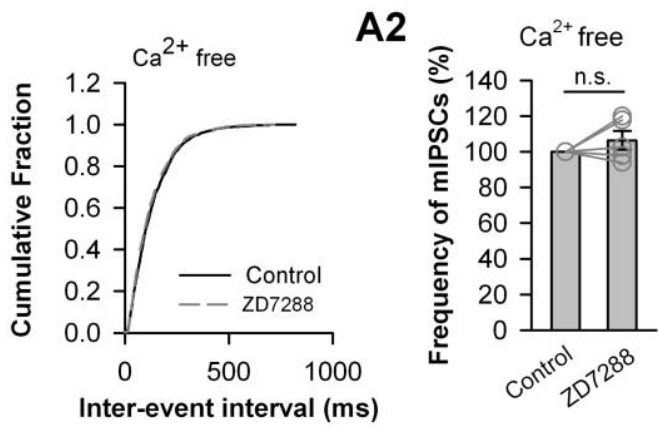

\section{B2}
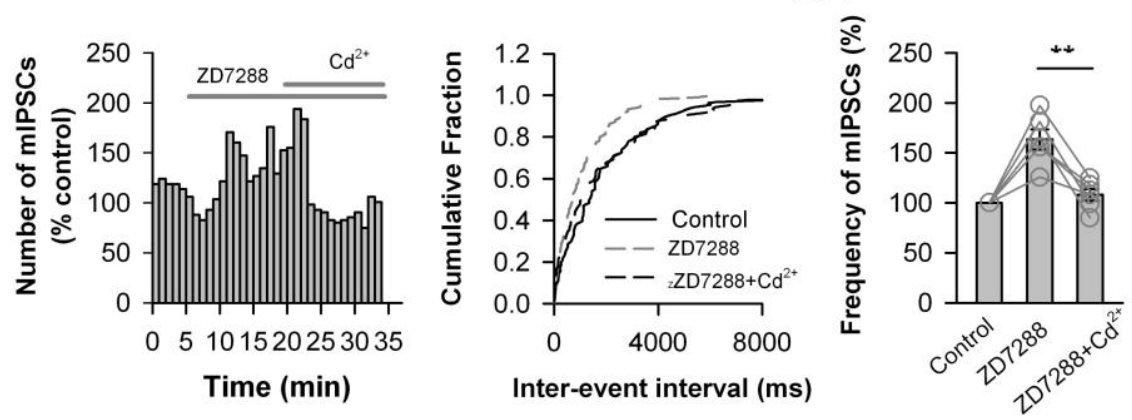

\section{HCN-blockade enhancement of mIPSC frequency requires $\mathrm{Ca}^{2+}$ influx.}

A. ZD7288 has no effect on mIPSC frequency under the condition of omitting extracellular $\mathrm{Ca}^{2+}$.

An example trace of miniature IPSCs (mIPSCs) recorded in pyramidal cell under $\mathrm{Ca}^{2+}$-free perfusion solution $(A 1$, left). The number distribution of mIPSCs (bin=60 s; A1, middle), and the cumulative fraction distribution of inter-event intervals of mIPSCs $(A 1$, right $)$ recorded from cell in left. The individual and grouped data showing the change in mIPSC frequency induced by ZD7288 under extracellular $\mathrm{Ca}^{2+}$-free condition. $\mathrm{n}=5$ pyramidal cells.

B. Blocking $\mathrm{Ca}^{2+}$ channel abolishes the effect of ZD7288 on mIPSC frequency. An example trace of miniature IPSCs (mIPSCs) recorded in pyramidal cell $(B 1$, left). The number distribution of mIPSCs (bin=60 s; B1, middle), and the cumulative fraction distribution of inter-event intervals of mIPSCs before (control), during application of ZD7288 alone (ZD7288), and during co-application of ZD7288 and $\mathrm{Ca}^{2+}$ channel blocker $\mathrm{Cd}^{2+}(200 \mu \mathrm{M}$, 
$\left.Z D 7288+C d^{2+}\right)(B 1$, right $)$ recorded from cell in left. The individual and grouped data showing the changes in mIPSC frequency induced by ZD7288 alone, and co-application of ZD7288 and $\mathrm{Cd}^{2+}(B 2) .{ }^{* *} \mathrm{p}<0.01, \mathrm{n}=6$ pyramidal cells. Calibrations: $5 \mathrm{~s}, 20 \mathrm{pA}$ in both A and B.

\section{Voltage-gated $\mathrm{Ca}^{2+}$ channels are involved in facilitation of GABA release by HCN blocking}

How loss the function in $\mathrm{HCN}$ channels increases $\mathrm{Ca}^{2+}$ influx? Considering that blockade of HCN channels hyperpolarizes membrane potential $[3,8]$, a possibility is that hyperpolarization of resting membrane potential results in voltage-sensitive $\mathrm{Ca}^{2+}$ channel (VGCC) open and thereby increasing $\mathrm{Ca}^{2+}$ influx into presynaptic terminals. To address this possibility, we hyperpolarized resting membrane potential by reducing external $\mathrm{K}^{+}$concentration from 2.5 to $1.75 \mathrm{mM}$, which, according to the Nernst equation, could hyperpolarize the resting membrane potential by $\sim 10 \mathrm{mV}$. As shown in Fig. 6A, such a reduction in external $\mathrm{K}^{+}$concentration resulted in hyperpolarization of membrane potential by $7.0 \pm 3.0 \mathrm{mV}$ ( $\mathrm{n}=6$ pyramidal cells), and induced an upregulation in mIPSC frequency by $168.94 \pm 7.28 \%$ of control $(p<0.01$, paired $t$-test; $n=5$ pyramidal cells from 3 animals). Thus, hyperpolarizing membrane potential mimics the effect of blocking HCN channels on mIPSC frequency.

Next step we want to figure out which type of VGCCs are involved in Blockade of HCN channels changes resting membrane potential and alters the activity of voltage-gated $\mathrm{Ca}^{2+}$ channels (VGCC), such as low voltage-activated T-type or high voltage-activated P/Q-type, $\mathrm{N}$-type, and L-type $\mathrm{Ca}^{2+}$ channels, resulting in $\mathrm{Ca}^{2+}$ influx into presynaptic terminals innervating pyramidal cells, and an increase in GABA release from the terminals.

$\mathrm{HCN}$ channels open at membrane potentials more negative to $-50 \mathrm{mV}$ and are important for regulating resting membrane potential. $\mathrm{HCN}$ channels are also permeable to $\mathrm{Na}^{+}$and $\mathrm{K}^{+}$and form an inward current at rest, thereby depolarizing resting membrane potential. Thus, it is possible 
that blockade of HCN channels changes resting membrane potential and alters the activity of lowvoltage-activated T-type or high-voltage-activated P/Q-type, N-type, and L-type $\mathrm{Ca}^{2+}$ channels, resulting in $\mathrm{Ca}^{2+}$ influx into presynaptic terminals innervating pyramidal cells, and an increase in GABA release from the terminals. To test this possibility, we examined whether the ZD7288-effect on mIPSC frequency could be occluded by $\mathrm{Ca}^{2+}$ channel blockers. As shown in Fig. 6, ZD7288 had on effect on mIPSC frequency in the presence of T-type $\mathrm{Ca}^{2+}$ channel blocker pimozide $(1 \mu \mathrm{M})$ [43] (Fig. 6B; $p<0.01$ for pimozide+ZD vs. pimozide, unpaired $t$-test). Additionally, Adding T-type Ca2+ channel blocker mibefradil (Mib; $10 \mu \mathrm{M}$ )[44] into perfusion solution occluded the facilitation effect of ZD7288 on mIPSC frequency ( $p>0.05)$, while perfusing Mib $(10 \mu \mathrm{M})$ alone did not affect the frequency of mIPSC $(\mathrm{p}>0.05)$. But the facilitation of ZD7288 on mIPSC frequency still exist in the presence of the P/Q-type $\mathrm{Ca}^{2+}$ channel blocker $\omega$-agatoxin IVA $(500 \mathrm{nM})$, the N-type $\mathrm{Ca}^{2+}$ channel blocker $\omega$-conotoxin GVIA (500 nM), and the L-type $\mathrm{Ca}^{2+}$ channel blocker nifedipine (Fig. $6 \mathrm{C} ; p>0.0$, one-way ANOVA). Together, these results indicate that blockade of HCN channels enhanced GABA release onto pyramidal cells by increasing $\mathrm{Ca}^{2+}$ influx through T-type $\mathrm{Ca}^{2+}$ channels. 


\section{Figure 6}

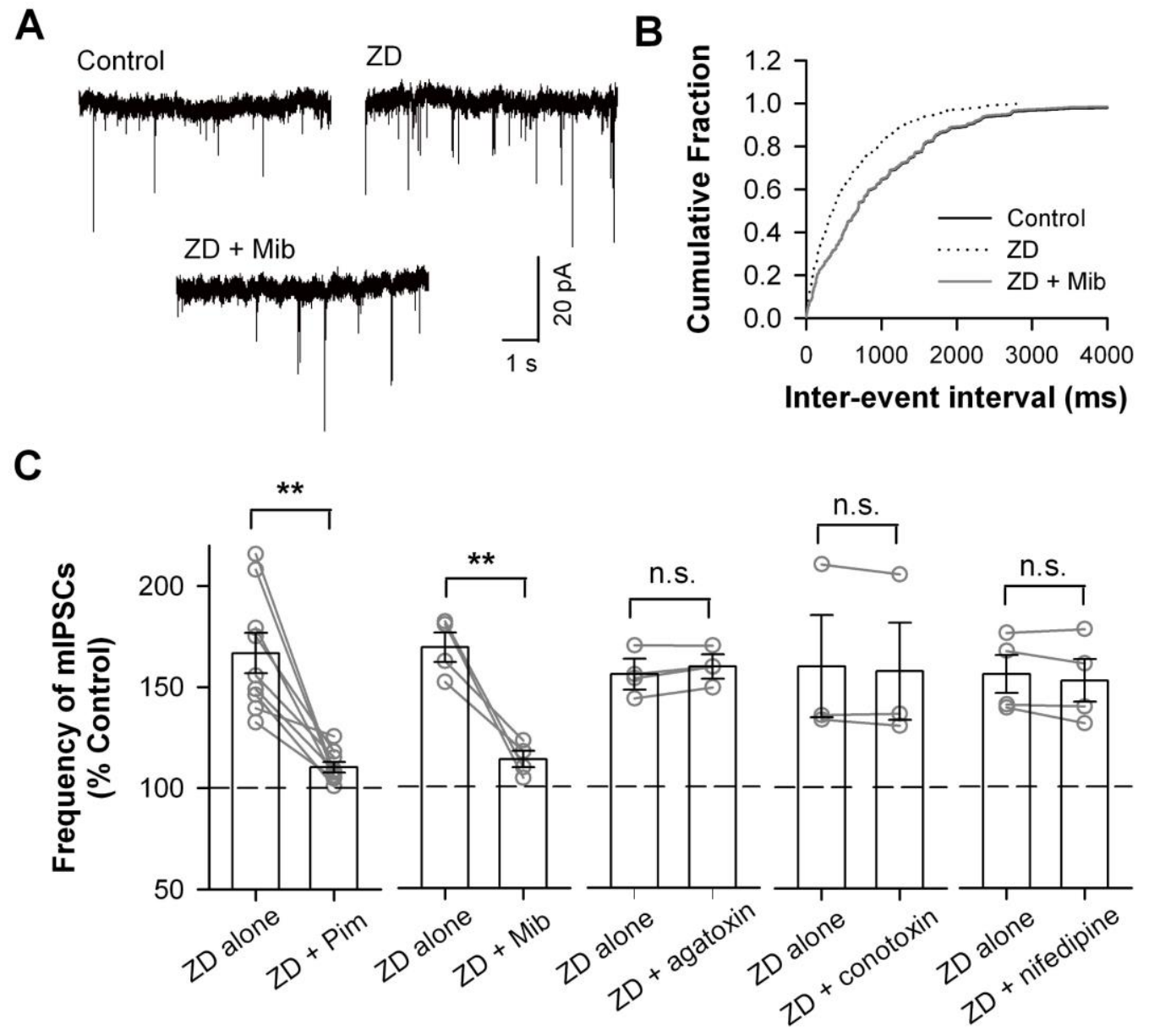

T-type Ca2+ channel blockers occlude the increment in mIPSC frequency induced by blocking

\section{HCN channels.}

A. Representative traces of mIPSCs recorded in pyramidal cell (left), and the cumulative fraction distribution of inter-event intervals of mIPSCs before (Control) and 8-10 min after hyperpolarization. Hyperpolarization of resting membrane potential by reducing external $\mathrm{K}^{+}$ concentration from $2.5 \mathrm{mM}$ (control) to $1.75 \mathrm{mM}$. Holding potential: $-70 \mathrm{mV}$. Calibration: $1 \mathrm{~s}$, 20 pA. $* * p<0.01 . n=4$ pyramidal cells.

B. the cumulative fraction distribution of inter-event intervals of mIPSCs recorded in pyramidal 
cell before (Control), during (ZD7288), and after co-application of ZD7288 with T-type $\mathrm{Ca}^{2+}$ channel selective blocker mibefradil (Mib; $10 \mu \mathrm{M})(Z D+M i b$; left $)$, Holding potential: -70 $\mathrm{mV}$.

C. Bar graph demonstrating the effects of co-application of ZD7288 $(30 \mu \mathrm{M})$ and Ca2+ channel blockers for T-type (pimozide, $1 \mu \mathrm{M}$; mibefradil, $10 \mu \mathrm{M}$ ), P/Q-type ( $\omega$-agatoxin IVA, 500 nM), N-type ( $\omega$-Conotoxin GVIA, $500 \mathrm{nM})$, and L-type (nifedipine, $2 \mathrm{mM}$ ) Ca2+ channels. Open circles for individual cells and bar for grouped data. $* * \mathrm{p}<0.01$, paired t-test.

\section{HCN channels express in parvalbumin-expressing basket cells}

To examine the expression of HCN channels in GABAergic interneurons in layer 5-6 of the mPFC, we conducted double-labeling immunofluorescence staining. Four HCN channel subunits, $\mathrm{HCN} 1, \mathrm{HCN} 2, \mathrm{HCN} 3$, and $\mathrm{HCN} 4$, have been cloned that contribute to brain $\mathrm{HCN}$ channels [45], and all the four HCN subunits are expressed in the mammalian brain, of which HCN3 exhibits the weakest expression [4]. As results presented in Fig. 1 and 2, blockade of HCN channels induced a dramatic increase in GABA release onto pyramidal cells were most likely generated from the soma of pyramidal neurons [29]. Interneurons expressing $\mathrm{Ca}^{2+}$-binding protein parvalbumin (PV) mainly innervate the soma of pyramidal cells and constitute the largest population of interneurons $(\sim 50 \%)$ in the prefrontal cortex $[21,23,29,46,47]$.

We double labeled HCN1, HCN2, and HCN4 subunit with PV. The confocal microscopy images demonstrated that HCN1-ir, HCN2-ir and HCN4-ir (green) abundantly co-localized with PV-ir (red) (Fig. 7A-C). The high-magnification images depicted that both HCN1-ir and HCN2-ir was observed in neurites of PV-ir cells, whereas no HCN4-ir was observed (Fig. 7D and E). Thus, $\mathrm{HCN} 1, \mathrm{HCN} 2$ and HCN4 subunit are all present in the cell bodies of PV-expressing interneurons, while only $\mathrm{HCN} 1$ and $\mathrm{HCN} 2$ express in the processing of PV-expressing interneurons in the layer 5-6 of the mPFC. 
Figure 7

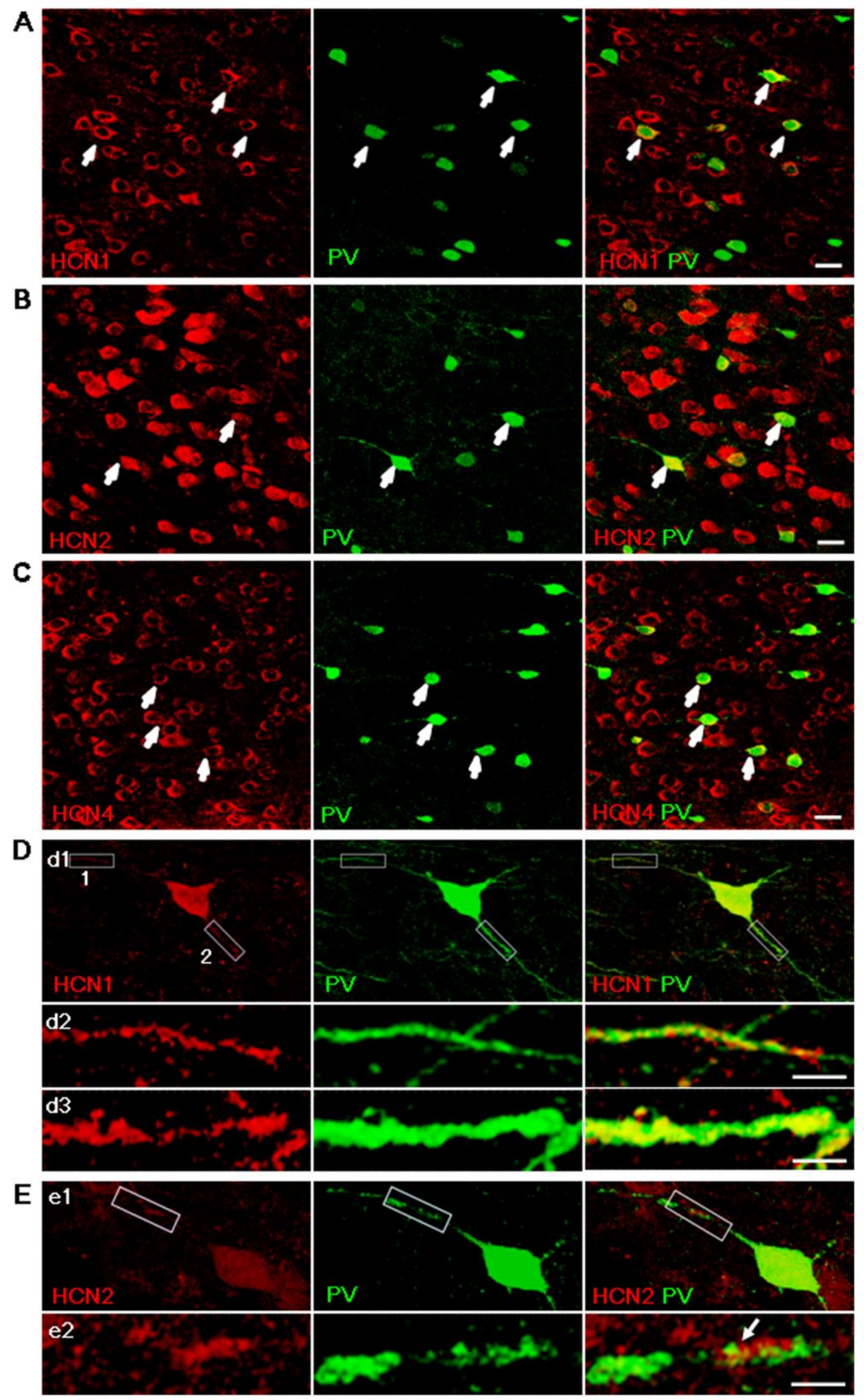


HCN channels are present in soma and neurite of parvalbumin-expressing basket cells in layer

\section{5-6 of $m P F C$.}

A-C. Microscopic confocal images showing HCN1-ir (A), HCN2-ir (B), and HCN4-ir $(C)$ locate in PV-ir interneuron in layer 5-6 of mPFC. Double stained with HCN channels (red) and PV (green). Arrowheads indicate double-labeled cells. Scale bar, $20 \mu \mathrm{m}$

D. High-magnification confocal microscopy images showing that HCN1-ir localize in the soma $(d 1)$ and along neurite $(d 2-d 3)$ of PV-ir interneuron. Silhouette frame 1 and 2 in neurite $(d l)$ is digital magnified for better view of neurite in $(d 2)$ and (d3), respectively. Scale bars, $20 \mu \mathrm{m}$ in $(d 1)$ and $1 \mu \mathrm{m}$ in $(d 2)$ and $(d 3)$.

E. High-magnification confocal microscopy images showing that HCN2-ir localize in the soma and along neurite of PV-ir interneuron. Silhouette frame in neurite (e1) is digital magnified for better view of neurite in (e2). Scale bars, $20 \mu \mathrm{m}$ in (e1) and $1 \mu \mathrm{m}$ in (e2). 


\section{Discussion}

In this study, we demonstrated that $\mathrm{HCN}$ channels are richly present in cells expressing parvalbumin, and pharmacological blocking HCN channels enhances GABA release onto pyramidal neurons in layer 5-6 of mPFC through increasing $\mathrm{Ca}^{2+}$ influx via T-type $\mathrm{Ca}^{2+}$ channels.

T-type $\mathrm{Ca}^{2+}$ channels are expressed in parvalbumin-expressing basket cells in the $5^{\text {th }}$ and $6^{\text {th }}$ cortical layers $[48,49]$, suggesting that $\mathrm{HCN}$ channels may provide a regulatory mechanism for controlling GABA releases from GABAergic terminals. It is reported that $\mathrm{HCN}$ channels regulates $\mathrm{T}$-type $\mathrm{Ca}^{2+}$ channel activity in neuronal dendrites in the hippocampus [50] and in layer 3 glutamate terminals in the entorhinal cortex $[16,17]$. Consistently, the present study demonstrated that $\mathrm{HCN}$ channels are present in the inhibitory presynaptic terminals of layer 5-6 basket cells in the mPFC, and constrain GABA release by restricting $\mathrm{Ca}^{2+}$ entry via pre-synaptic T-type $\mathrm{Ca}^{2+}$ channels.

The universality and nonselective cation permeability make HCN channels indispensable for cell excitability. Not only in pyramidal neurons, interneurons excitability homeostasis disorder also can trigger psychosis[51, 52]. Simultaneously, HCN channels engage on intracellular cascade reaction, like work as a downstream of some neurotransmitter receptors such as alpha-2 $\left(\alpha_{2}\right)$ adrenergic receptor, and the location of HCN channels in post-synapse membrane also facilitate they involve in synaptic signaling[28]. Along this principle, the specific expression of $\mathrm{HCN}$ channels in parvalbumin-expressing basket cells suggests it may involve in GABA release[53]. Our study consistence with this point and prove this pathway regulate the inhibitory input of layer 5-6 pyramidal neuron in mPFC. Beside alpha-2 $\left(\alpha_{2}\right)$ adrenergic receptor, HCN channels may also can be regulated by other neurotransmitter receptor such as dopamine receptor through cAMP pathway. Combine these together, some neurotransmitters would regulate GABAergic transmission by means of affecting HCN channels to control cortex rhythmic oscillatory, which is essential for brain functional running. 
Regulation of GABA release by HCN channels is diverse, dependent on their locations and proximity to other ion channels. It is reported that, in the entorhinal cortex and globus pallidus, blockade or loss of HCN channels induces an increase in the frequency of sIPSCs and mIPSCs, with no effect on the amplitude of mIPSCs $[12,54]$, similar with what we found in the present study. However, some other studies showed that pharmacological blockade of HCN channels with ZD7288 results in a reduction, instead of increase, in the frequency of sIPSCs or mIPSCs in the CA1 and DG regions of the hippocampus and in the cerebellum as well $[18,19,55]$. Such discrepancy might be due to that, the presynaptic $\mathrm{HCN}$ channels exerts depolarizing influence on GABAergic terminals, and that blockade of HCN channels inhibits neurotransmitters release via hyperpolarization. Indeed, an increase in the external $\mathrm{K}^{+}$concentration from 2.5 to $5.0 \mathrm{mM}$ reverses the inhibitory effect of HCN-channel blockade on mIPSC frequency [18].

Although pyramidal cells in the mPFC receive inhibitory inputs from several types of interneurons [56], the present results suggest that the increase in sIPSC/mIPSC frequency induced by $\mathrm{HCN}$-channel blockade was mainly originated from increased release of GABA from parvalbumin-expressing basket cells. First, as the source of the dominant inhibitory system with the largest population of interneurons in layer 5-6 of the prefrontal cortex [21], parvalbumin-expressing basket cells should inevitably produce largest somatically-recorded IPSCs $[23,47]$. Thus, the frequency of sIPSCs with large amplitude should increase dramatically upon GABA release from parvalbumin-expressing basket cells in the presence of ZD7288. Indeed, our data showed that the ZD7288-induced increase in the frequency of large sIPSCs (with amplitude larger than $20 \mathrm{pA}$ ) was up to $183.06 \pm 21.07 \%$ of control, whereas that of all detective sIPSCs was only $135.34 \pm 10.22 \%$. Second, ZD7288 augmented the frequency but not the amplitude or kinetics of mIPSCs (see Figure 2E), suggesting that GABA was released tonically from the GABAergic terminals close to the soma of the pyramidal cells [29]. Third, it has been shown that interneurons that do not express parvalbumin make synapses near the soma of 
pyramidal cells and utilize $\mathrm{N}$-type $\mathrm{Ca}^{2+}$ channels in terminals for GABA release, while parvalbumin-expressing interneurons utilize P/Q-type $\mathrm{Ca}^{2+}$ channels in terminals for GABA release $[57,58]$. Our data showed that ZD7288 still increased the frequency of mIPSCs in the presence of the N-type $\mathrm{Ca}^{2+}$ channel blocker (see Figure 6C). Taken together, we argue that parvalbumin-expressing basket cells produced the major contribution to the ZD7288-induced increase in spontaneous/miniature IPSCs in layer 5-6 pyramidal cells.

Parvalbumin-expressing basket cells in the cortex play an important role in adjusting the gain of synaptic inputs onto and controlling synchronization and excitatory output of pyramidal cells, and through this mechanism, they control both the number of pyramidal cells activated and the firing frequency of the pyramidal cells[59]. Pyramidal cells in layer 5-6 of the mPFC have been suggested to primarily project to subcortical regions to regulate complex motor functions, behavioral arousal and attention [60]. The dynamic modulation of GABAergic inputs to the pyramidal cells by HCN channels in parvalbumin-expressing basket cells may contribute to the regulation of these physiological states. In addition, oscillations occurring in PFC pyramidal cells are essential for behavioral and cognitive functions [61]. Coherent network oscillations, which are facilitated by GABA released onto pyramidal cells, are required for execution of cognitive functions. Abnormal $\gamma$-frequency oscillations observed in schizophrenia has been suggested to be due to a reduction in peri-somatic inhibition in PFC pyramidal cells [62]. Thus, HCN channels in parvalbumin-expressing basket cells might be a potential target for drug development for schizophrenia. 


\section{Materials and Methods}

\section{Electrophysiology}

Male Sprague-Dawley rats (4-5 weeks old, 80-130 g) were purchased from SLACCAS (Shanghai, China) and were kept in a $12 \mathrm{~h}$ light/dark cycle, and food and water were available ad libitum. All experiments were performed in compliance with the Guide for the Care and Use of Laboratory Animals issued by the National Institutes of Health, USA, and were approved and monitored by the Ethical Committee of Animal Experiments at the Fudan University Institute of Neurobiology (Shanghai, China). All efforts were made to minimize the number of animals used and their suffering.

Rats were anesthetized with pentobarbital sodium (40 mg/kg, i.p.) and rapidly decapitated. Brains were quickly removed and immersed in the $0^{\circ} \mathrm{C}$ artificial cerebrospinal fluid (ACSF) solution containing (in $\mathrm{mM}$ ): $119 \mathrm{NaCl}, 2.5 \mathrm{KCl}, 2.5 \mathrm{CaCl} 2,1.3 \mathrm{MgCl} 2,26.2 \mathrm{NaHCO}, 1.25$ NaH2PO4 and 11 D-glucose. Coronal brain slices $(300 \mu \mathrm{m})$ containing the prelimbic cortex (Paxinos and Watson, 5th edition) were cut on a vibratome tissue slicer (Ted Pella Inc., USA) and transferred to incubation chamber, where they were incubated in ACSF solution for at least $1 \mathrm{hr}$ at room temperature before recording. The ACSF solution was constantly bubbled with $95 \%$ $\mathrm{O} 2-5 \% \mathrm{CO} 2$ to maintain $\mathrm{pH} 7.4$.

Whole-cell current-clamp recordings were performed using standard procedures at room temperature. Brain slices were transferred to a submersion-type chamber and perfused constantly ( $2 \mathrm{ml} / \mathrm{min}$ ) with ACSF. Layer 5-6 pyramidal cells were visualized using an Olympus BX51 microscope equipped with IR-DIC optics and an infrared video camera (Qimaging, Canada). Current-clamp recordings were obtained using Axon 200B amplifier, Digidata 1322 A/D converter and pClamp software (Molecular Devices, USA). Recordings were not corrected for the liquid junction potential. Data were discarded if Ra was altered by $\sim 20 \%$. For IPSC recordings, external perfusion solution contained AMPA receptor antagonist CNQX or DNQX (20 $\mu \mathrm{M})$ and 
NMDA receptor antagonist APV $(50 \mu \mathrm{M})$. The pipette solution contained (in $\mathrm{mM}) 70$ K-gluconate, $70 \mathrm{KCl}, 20 \mathrm{HEPES}, 0.5 \mathrm{CaCl}_{2}$, 5.0 EGTA, $5 \mathrm{Mg}$-ATP, and its $\mathrm{pH}$ was adjusted to 7.2 with $\mathrm{KOH}$. The pipette resistance, as measured in the bath, was typically 2.0-3.0 M $\Omega$. Ion channel blockers used in this study were applied by bath perfusion for at least 10 min unless otherwise noted. To assess the role of HCN channels in GABAergic transmission, the HCN channel blocker ZD7288 was applied after 5 10 min baseline recording. ZD7288-induced changes in GABAergic transmission were measured in the last 3 min of the 15-min perfusion of ZD7288 unless otherwise mentioned.

\section{Chemicals}

All reagents were purchased from the Sigma Chemical Company (St. Louis, MO) with the exceptions of ZD7288 from the Tocris company (UK), $\omega$-Agatoxin IVA, $\omega$-Conotoxin GVIA and pimozide from Alomone Labs (Isreal). All channel blockers were prepared as concentrated stock solutions in distilled water or DMSO and either added immediately to ACSF at working concentrations or stored at $-20^{\circ} \mathrm{C}$ for subsequent utilization.

\section{Immunostaining}

Age-matched male Sprague-Dawley rats were anesthetized with pentobarbital sodium (40 $\mathrm{mg} / \mathrm{kg}$, i.p.), and transcardial perfusion was performed with $34^{\circ} \mathrm{C}$ saline $(200 \mathrm{ml})$ followed by $4 \%$ ice-cold paraformaldehyde (PFA) in phosphate-buffered saline (PBS, pH 7.4). Brains were removed and were fixed for $24 \mathrm{~h}$ in PFA at $4^{\circ} \mathrm{C}$. After that, the brains were put in $30 \%(\mathrm{w} / \mathrm{v})$ sucrose solution. Coronal sections $(35 \mu \mathrm{m})$ were cut using a cryostat (Leica CM900, Germany). Brain sections were rinsed with $0.01 \mathrm{M}$ PBS and incubated in a solution of $0.5 \%$ Triton-X in PBS for $15 \mathrm{~min}$, followed by normal blocking solution (goat serum, Invitrogen) for $2 \mathrm{~h}$ at room temperature. Sequential primary immunolabeling for $\mathrm{HCN} 1, \mathrm{HCN} 2$ or $\mathrm{HCN} 4$ was performed using anti-HCN1, HCN2 or HCN4 rabbit antibodies (1:40; Alomone Laboratories, Israel, 
Product\# APC-056, APC-030, APC-057) [63]. GABAergic neurons were labeled using anti-parvalbumin mouse antibody (PARV-19, 1:1000; Sigma, St. Louis, MO, USA, Product\# P3088). All primary antibodies were diluted in goat serum (Invitrogen) and incubated $48 \mathrm{~h}$ at $4{ }^{\circ} \mathrm{C}$. After 48-h incubation, the brain sections were rinsed with PBS, and an appropriate secondary antibody was applied. Fluorescent secondary antibodies (whole IgG affinity-purified antibodies: Goat anti-rabbit FITC, Goat anti-mouse Texas Red and Goat anti-mouse FITC; all from Jackson ImmunoResearch Laboratories, West Grove, PA, USA) were applied at a 1:100 dilution in normal blocking serum for $2 \mathrm{~h}$ at $4{ }^{\circ} \mathrm{C}$.

\section{Confocal microscopy}

Immunolabeled sections were examined using a confocal laser-scanning microscope system (Leica SP2, Mannheim, Germany). FITC and Texas Red fluorochromes were excited at $488 \mathrm{~nm}$ and $543 \mathrm{~nm}$ wavelengths, respectively, and the fluorescent emission was collected through BP 505-530 and BP 560-615 filters, respectively. Twelve-bit images were captured at a resolution of $1024 \times 1024$ pixels using a $20 \times$ objective and at $1024 \times 1024$ pixels with a Plan-Apochromat $63 / 1.4$ oil-immersion. Immunoreactivity (IR) was examined under optimal resolution (small pinhole, thin optical slice, and high numerical aperture oil-immersion objective). The pinhole diameter was set to 1.5 airy unit to reduce the influence of cytoplasmic fluorescence as much as possible. Z-sectioning was performed at 0.5 - $\mu \mathrm{m}$ intervals, and stacks of optical sections at the $z$ axis were acquired. For comparison of the distribution of HCN1, HCN2 and HCN4 channels, each micrograph was captured using the same settings for laser power, pinhole, and photo-multiplier gain. Confocal photomicrographs were processed using Adobe Photoshop (San Jose, CA, USA). No immunolabeling was observed in control slices in which the primary antibody was omitted. The multi-tracking configuration was employed to rule out crosstalk between the fluorescent detection channels. 


\section{Data analysis and statistics}

Data are expressed as mean \pm SEM in all cases. The frequency and amplitude of sIPSCs/mIPSCs were analyzed using the Mini Analysis software package (v8.0, Synaptosoft, Leonia, NJ, http://www.synaptosoft.com). Events above five-fold baseline noise level in amplitude were detected and were used for analysis. Drug-induced changes in cumulative fractions of sIPSC/mIPSC amplitude and inter-event interval were analyzed for statistical significance using the Kolmogorov-Smirnov (K-S) test (Mini Analysis v8.0) and a conservative critical probability level of $p<0.01$. Grouped data were analyzed using paired or unpaired $t$-test for two-group comparison, one-way ANOVA for multi-group comparison, and a critical probability of $p<0.05$ (STATISTICA 6.0, USA). 


\section{Acknowledgements}

The present study was supported by grants from the Ministry of Science and Technology of China (2006CB500807; 2011CBA00406 to BML), the National Natural Science Foundation of China (30990263, 30821002, 31121061 to BML, 30700218 to XHZ) and Open Research Fund of the Key Laboratory of Brain Functional Genomics, Ministry of Education (XHZ).

\section{Competing interests}

The authors declare no competing or financial interests. 


\section{Reference}

[1] B.S.a.G.R. TIBBS, <he HCN gene family molecular basis of the hyperpolarization activated pacemaker channels.pdf, (1999).

[2] M. Baruscotti, D. Difrancesco, Pacemaker channels, Ann N Y Acad Sci 1015 (2004) 111-21.

[3] M. Biel, C. Wahl-Schott, S. Michalakis, X. Zong, Hyperpolarization-activated cation channels: from genes to function, Physiol Rev 89(3) (2009) 847-85.

[4] R.B. Robinson, S.A. Siegelbaum, Hyperpolarization-activated cation currents: from molecules to physiological function, Annu Rev Physiol 65 (2003) 453-80.

[5] A. Lorincz, T. Notomi, G. Tamas, R. Shigemoto, Z. Nusser, Polarized and compartment-dependent distribution of HCN1 in pyramidal cell dendrites, Nat Neurosci 5(11) (2002) 1185-93.

[6] R. Gauss, R. Seifert, Pacemaker oscillations in heart and brain: a key role for hyperpolarization-activated cation channels, Chronobiol Int 17(4) (2000) 453-69.

[7] H.C. Pape, Queer current and pacemaker: the hyperpolarization-activated cation current in neurons, Annu Rev Physiol 58 (1996) 299-327.

[8] M. Day, D.B. Carr, S. Ulrich, E. Ilijic, T. Tkatch, D.J. Surmeier, Dendritic excitability of mouse frontal cortex pyramidal neurons is shaped by the interaction among HCN, Kir2, and Kleak channels, J Neurosci 25(38) (2005) 8776-87.

[9] T. Notomi, R. Shigemoto, Immunohistochemical localization of Ih channel subunits, HCN1-4, in the rat brain, J Comp Neurol 471(3) (2004) 241-76.

[10] M.M. Shah, Cortical HCN channels: function, trafficking and plasticity, J Physiol 592(13) (2014) 2711-9.

[11] R.A. Bender, T. Kirschstein, O. Kretz, A.L. Brewster, C. Richichi, C. Ruschenschmidt, R. Shigemoto, H. Beck, M. Frotscher, T.Z. Baram, Localization of HCN1 channels to presynaptic compartments: novel plasticity that may contribute to hippocampal maturation, J Neurosci 27(17) (2007) 4697-706.

[12] J. Boyes, J.P. Bolam, R. Shigemoto, I.M. Stanford, Functional presynaptic HCN channels in the rat globus pallidus, The European journal of neuroscience 25(7) (2007) 2081-92.

[13] R. Lujan, J.L. Albasanz, R. Shigemoto, J.M. Juiz, Preferential localization of the hyperpolarization-activated cyclic nucleotide-gated cation channel subunit HCN1 in basket cell terminals of the rat cerebellum, Eur J Neurosci 21(8) (2005) 2073-82.

[14] V. Beaumont, N. Zhong, R.C. Froemke, R.W. Ball, R.S. Zucker, Temporal synaptic tagging by I(h) activation and actin: involvement in long-term facilitation and cAMP-induced synaptic enhancement, Neuron 33(4) (2002) 601-13.

[15] V. Beaumont, R.S. Zucker, Enhancement of synaptic transmission by cyclic AMP modulation of presynaptic Ih channels, Nat Neurosci 3(2) (2000) 133-41.

[16] Z. Huang, R. Lujan, I. Kadurin, V.N. Uebele, J.J. Renger, A.C. Dolphin, M.M. Shah, Presynaptic HCN1 channels regulate Cav3.2 activity and neurotransmission at select cortical synapses, Nat Neurosci 14(4) 478-86.

[17] Z. Huang, R. Lujan, I. Kadurin, V.N. Uebele, J.J. Renger, A.C. Dolphin, M.M. Shah, Presynaptic HCN1 channels regulate Cav3.2 activity and neurotransmission at select cortical synapses, Nat Neurosci 14(4) (2011) 478-86.

[18] Y. Aponte, C.C. Lien, E. Reisinger, P. Jonas, Hyperpolarization-activated cation channels in fast-spiking interneurons of rat hippocampus, J Physiol 574(Pt 1) (2006) 229-43.

[19] A.P. Southan, N.P. Morris, G.J. Stephens, B. Robertson, Hyperpolarization-activated currents in presynaptic terminals of mouse cerebellar basket cells, J Physiol 526 Pt 1 (2000) 91-7.

[20] C.J. McBain, A. Fisahn, Interneurons unbound, Nat Rev Neurosci 2(1) (2001) 11-23.

[21] Y. Gonchar, A. Burkhalter, Three distinct families of GABAergic neurons in rat visual cortex, Cereb Cortex 7(4) (1997) 347-58.

[22] T.F. Freund, I. Katona, Perisomatic inhibition, Neuron 56(1) (2007) 33-42.

[23] H. Markram, M. Toledo-Rodriguez, Y. Wang, A. Gupta, G. Silberberg, C. Wu, Interneurons of the neocortical inhibitory system, Nature reviews 5(10) (2004) 793-807.

[24] E.H. Buhl, K. Halasy, P. Somogyi, Diverse sources of hippocampal unitary inhibitory postsynaptic potentials and the number of synaptic release sites, Nature 368(6474) (1994) 823-8.

[25] M. Bartos, I. Vida, P. Jonas, Synaptic mechanisms of synchronized gamma oscillations in inhibitory interneuron networks, Nature reviews 8(1) (2007) 45-56. 
[26] J.E. Lisman, J.T. Coyle, R.W. Green, D.C. Javitt, F.M. Benes, S. Heckers, A.A. Grace, Circuit-based framework for understanding neurotransmitter and risk gene interactions in schizophrenia, Trends Neurosci 31(5) (2008) 234-42.

[27] J. Lisman, Excitation, inhibition, local oscillations, or large-scale loops: what causes the symptoms of schizophrenia?, Current opinion in neurobiology (2011).

[28] M. Wang, B.P. Ramos, C.D. Paspalas, Y. Shu, A. Simen, A. Duque, S. Vijayraghavan, A. Brennan, A. Dudley, E. Nou, J.A. Mazer, D.A. McCormick, A.F. Arnsten, Alpha2A-adrenoceptors strengthen working memory networks by inhibiting cAMP-HCN channel signaling in prefrontal cortex, Cell 129(2) (2007) 397-410.

[29] I. Soltesz, D.K. Smetters, I. Mody, Tonic inhibition originates from synapses close to the soma, Neuron 14(6) (1995) 1273-83.

[30] G. Maccaferri, M. Mangoni, A. Lazzari, D. DiFrancesco, Properties of the hyperpolarization-activated current in rat hippocampal CA1 pyramidal cells, J Neurophysiol 69(6) (1993) 2129-36.

[31] J.C. Magee, Dendritic hyperpolarization-activated currents modify the integrative properties of hippocampal CA1 pyramidal neurons, J Neurosci 18(19) (1998) 7613-24.

[32] T. Berger, M.E. Larkum, H.R. Luscher, High I(h) channel density in the distal apical dendrite of layer V pyramidal cells increases bidirectional attenuation of EPSPs, J Neurophysiol 85(2) (2001) 855-68.

[33] H. Fiorentino, N. Kuczewski, D. Diabira, N. Ferrand, M.N. Pangalos, C. Porcher, J.L. Gaiarsa, $\mathrm{GABA}(\mathrm{B})$ receptor activation triggers BDNF release and promotes the maturation of GABAergic synapses, J Neurosci 29(37) (2009) 11650-61.

[34] C. Schwab, S. Yu, W. Wong, E.G. McGeer, P.L. McGeer, GAD65, GAD67, and GABAT immunostaining in human brain and apparent GAD65 loss in Alzheimer's disease, J Alzheimers Dis 33(4) (2013) 1073-88.

[35] Y.C. Liu, Y.J. Wang, P.Y. Wu, S.N. Wu, Tramadol-induced block of hyperpolarization-activated cation current in rat pituitary lactotrophs, Naunyn Schmiedebergs Arch Pharmacol 379(2) (2009) 127-35.

[36] J.L. Sanchez-Alonso, J.V. Halliwell, A. Colino, ZD 7288 inhibits T-type calcium current in rat hippocampal pyramidal cells, Neurosci Lett 439(3) (2008) 275-80.

[37] A. Ludwig, X. Zong, M. Jeglitsch, F. Hofmann, M. Biel, A family of hyperpolarization-activated mammalian cation channels, Nature 393(6685) (1998) 587-91.

[38] S. Chen, J. Wang, S.A. Siegelbaum, Properties of hyperpolarization-activated pacemaker current defined by coassembly of HCN1 and HCN2 subunits and basal modulation by cyclic nucleotide, J Gen Physiol 117(5) (2001) 491-504.

[39] C. Ulens, J. Tytgat, Functional heteromerization of HCN1 and HCN2 pacemaker channels, J Biol Chem 276(9) (2001) 6069-72.

[40] B.J. Wainger, M. DeGennaro, B. Santoro, S.A. Siegelbaum, G.R. Tibbs, Molecular mechanism of cAMP modulation of HCN pacemaker channels, Nature 411(6839) (2001) 805-10.

[41] J. Stieber, S. Herrmann, S. Feil, J. Loster, R. Feil, M. Biel, F. Hofmann, A. Ludwig, The hyperpolarization-activated channel HCN4 is required for the generation of pacemaker action potentials in the embryonic heart, Proc Natl Acad Sci U S A 100(25) (2003) 15235-40.

[42] E.T. Kavalali, The mechanisms and functions of spontaneous neurotransmitter release, Nat Rev Neurosci 16(1) (2015) 5-16.

[43] Maho Tsubota, Kazuki Matsui, S. Fukushi, Effects of Bepridil and Pimozide, Existing Medicines Capable of Blocking T-Type Ca2+ Channels, on Visceral Pain in Mice, Biol Pharm Bull (2021).

[44] L. Wan, W. Wu, S. Jiang, S. Wan, D. Meng, Z. Wang, J. Zhang, L. Wei, P. Yu, Mibefradil and Flunarizine, Two T-Type Calcium Channel Inhibitors, Protect Mice against Lipopolysaccharide-Induced Acute Lung Injury, Mediators Inflamm 2020 (2020) 3691701.

[45] D.E. Clapham, Not so funny anymore: pacing channels are cloned, Neuron 21(1) (1998) 5-7.

[46] C.P. Wonders, S.A. Anderson, The origin and specification of cortical interneurons, Nature reviews 7(9) (2006) 687-96.

[47] Y. Kawaguchi, Y. Kubota, GABAergic cell subtypes and their synaptic connections in rat frontal cortex, Cereb Cortex 7(6) (1997) 476-86.

[48] X.B. Liu, K.D. Murray, E.G. Jones, Low-threshold calcium channel subunit Ca(v) 3.3 is specifically localized in GABAergic neurons of rodent thalamus and cerebral cortex, The Journal of comparative neurology 519(6) (2011) 1181-95.

[49] X.B. Liu, K.D. Murray, E.G. Jones, Low-threshold calcium channel subunit Ca(v) 3.3 is specifically localized in GABAergic neurons of rodent thalamus and cerebral cortex, J Comp Neurol 519(6) 1181-95. 
[50] D. Tsay, J.T. Dudman, S.A. Siegelbaum, HCN1 channels constrain synaptically evoked Ca2+ spikes in distal dendrites of CA1 pyramidal neurons, Neuron 56(6) (2007) 1076-89.

[51] S.J. Choi, T.C. Ma, Y. Ding, T. Cheung, N. Joshi, D. Sulzer, E.V. Mosharov, U.J. Kang, Alterations in the intrinsic properties of striatal cholinergic interneurons after dopamine lesion and chronic L-DOPA, Elife 9 (2020).

[52] W. Lin, J. Qin, G. Ni, Y. Li, H. Xie, J. Yu, H. Li, L. Sui, Q. Guo, Z. Fang, L. Zhou, Downregulation of hyperpolarization-activated cyclic nucleotide-gated channels (HCN) in the hippocampus of patients with medial temporal lobe epilepsy and hippocampal sclerosis (MTLE-HS), Hippocampus 30(10) (2020) 1112-1126.

[53] F.C. Roth, H. Hu, An axon-specific expression of HCN channels catalyzes fast action potential signaling in GABAergic interneurons, Nat Commun 11(1) (2020) 2248.

[54] Z. Huang, M.C. Walker, M.M. Shah, Loss of dendritic HCN1 subunits enhances cortical excitability and epileptogenesis, J Neurosci 29(35) (2009) 10979-88.

[55] C.R. Lupica, J.A. Bell, A.F. Hoffman, P.L. Watson, Contribution of the hyperpolarization-activated current $(\mathrm{I}(\mathrm{h}))$ to membrane potential and GABA release in hippocampal interneurons, J Neurophysiol 86(1) (2001) 261-8.

[56] T.F. Freund, G. Buzsaki, Interneurons of the hippocampus, Hippocampus 6(4) (1996) 347-470.

[57] R.I. Wilson, G. Kunos, R.A. Nicoll, Presynaptic specificity of endocannabinoid signaling in the hippocampus, Neuron 31(3) (2001) 453-62.

[58] S. Hefft, P. Jonas, Asynchronous GABA release generates long-lasting inhibition at a hippocampal interneuron-principal neuron synapse, Nat Neurosci 8(10) (2005) 1319-28.

[59] F.P.M. Scanziani, Routing of spike series by dynamic circuits in the hippocampus, (2004).

[60] P.L. Gabbott, T.A. Warner, P.R. Jays, P. Salway, S.J. Busby, Prefrontal cortex in the rat: projections to subcortical autonomic, motor, and limbic centers, J Comp Neurol 492(2) (2005) 145-77.

[61] M.J. Jutras, E.A. Buffalo, Synchronous neural activity and memory formation, Curr Opin Neurobiol 20(2) 150-5.

[62] D.A. Lewis, K.N. Fish, D. Arion, G. Gonzalez-Burgos, Perisomatic inhibition and cortical circuit dysfunction in schizophrenia, Curr Opin Neurobiol.

[63] N.P. Morris, R.E. Fyffe, B. Robertson, Characterisation of hyperpolarization-activated currents (I(h)) in the medial septum/diagonal band complex in the mouse, Brain Res 1006(1) (2004) 74-86. 